\title{
Food Safety Management in Ukraine in the Context of the International Standard ISO 22000:2005
}

\author{
Usenko Anatoliy, Julia Iurynets, Yuriy Pyvovar, Leonid Belkin
}

\begin{abstract}
The article examines the features of the Hazard Analysis and Critical Control Points (HACCP) system as a factor in food safety. The principles of $\mathrm{HACCP}$, formulated in the ISO 22000: 2005 standard, in the Alimentations Commission Codex are compared, as well as in accordance with the Ukrainian regulatory document "Requirements for the development of food safety standards", approved by the Order of the Ministry of Health of Ukraine on October 1, 2012 No. 590. The comparison is carried out in order to establish the compliance of the Ukrainian HACCP system with the international rules, in particular the ISO 22000: 2005 standard. Shown, that the principles of the Ukrainian HACCP system generally comply with international standards, in particular ISO 22000: 2005. This means that the legislation of Ukraine guarantees that, in compliance with it, food products originating from Ukraine comply with international requirements for the control of its manufacture. The guarantee of this is the system of control measures that are provided for by the laws of Ukraine regarding compliance with the requirements of the HACCP system.
\end{abstract}

Keywords: Food Safety; Legislative Regulation; Hazard Analysis and Critical Control Points; Administrative and Legal Framework

\section{INTRODUCTION}

The problem of food safety has always been acutely urgent, and therefore one of the most discussed in different areas of science and technology, as well as administrative management ${ }^{\mathrm{i}, \mathrm{ii}, \mathrm{iii}, \mathrm{iv}}$ Recently, among manufacturers and, especially, consumers, it has become a determining opinion that an adequate level of quality can be ensured not only by controlling the final product, but also by monitoring throughout the production chain. This monitoring system was called Hazard Analysis and Critical Control Points (HACCP).

The EU considers HACCP to be the most effective method of ensuring food safety and requires all food industry enterprises to implement, maintain and implement procedures based on the HACCP principles."

Ukraine, as a country that seeks to enter the EU food

Revised Manuscript Received on September 22, 2019.

Usenko Anatoliy, Ph.D student, National Aviation University, Kyiv, Ukraine

Julia Iurynets, Dsc., Assoc. Prof., National Aviation University, Kyiv, Ukraine

Yuriy Pyvovar, Ph.D., Prof., National Aviation University, Kosmonavta Komarova str. 1, 03058 Kyiv, Ukraine. pyvovaryi@gmail.com

Leonid Belkin, Ph.D., Self-employed person, Kyiv, Ukraine. market, is making certain efforts, including administrative and legal, regarding the use of HACCP at food industry enterprises, as well as responsibility for ignoring the relevant rules. Separate works on these issues belong to the co-author A. Usenko. vi,vii

In particular, according to clause 5 of the Procedure for Issuing International Veterinary Certificates for the Export of Poultry to the EU Member States, approved by the Order of the State Committee for Veterinary Medicine dated December 17, 2009 No. 535, the mandatory condition for the export of poultry meat to the EU countries is the introduction on the facilities (objects) of HACCP systems or similar systems for ensuring the safety and quality of products.

Thus, the Ukrainian state guarantees that, in particular, poultry meat, which is legally exported from Ukraine to the EU countries, is produced at production facilities where the HACCP control system is implemented.

The main Law of Ukraine, which currently regulates compliance with food safety requirements, is Law No. 771/97-BP, which currently operates as amended by Law No. 1602-VII of 22.07.2014. At the same time, the norms of the HACCP system were reflected in Law No. 771/97-BP even in its first edition (dated 12.23.1997), and in a modern form regarding the requirements of HACCP were brought changes by Act No. 2809-IV of 06.09.2005. In the current version of the Law on 22.07.2014, the most systematic legislative regulation of the HACCP system was introduced: this definition is a system that identifies, assesses and controls the hazardous factors that are critical to the safety of food products (Section 81, Paragraph 1, Clause 1); the mandatory introduction of the HACCP system at the enterprises of the food industry is foreseen (Section 2 Part 1 Article 20); requirements for application of constantly operating procedures, based on the principles of a system of analysis of dangerous factors and control at critical points (Article 21); provides for responsibility for failure to fulfill the statutory obligation to implement on the capabilities of the system HACCP (Clause 4, Part 1, Article 64). However, Final and Transitional Provisions (subsection 1, paragraph 1) of the Law No. 1602-VII provide for a gradual transition to the mandatory introduction of HACCP systems:

- capacities that carry out activities with food products, which contain unprocessed ingredients of animal origin (except for small capacities), - three years from the day 
following the day of publication of this Law (from 20.09.2017);

- capacities that carry out activities with foodstuffs, which contain no unprocessed ingredients of animal origin (except for small capacities), four years from the day following the day of the publication of this Law (from 20.09.2018);

- small capacities - five years from the day following the day of publication of this Law (from 20.09.2019). In accordance with paragraph 37 of Part 1 of Art. 1 of the Law of Ukraine No. 771/97-BP in the current edition, small capacity capacity, which supplies food products to the end user, have no more than ten employees, occupy an area no more than 400 square meters, or power that does not supply food to the final consumer and have no more than five employees.

Under these conditions, it is advisable to consider whether the Ukrainian system complies with European standards, which is the purpose of this article.

\section{RESUltS AND Findings}

The international standard ISO 22000: 2005 (International Organization for Standardization, 2018) was intended to unify current control procedures by monitoring the entire production chain. The procedures are based on the fact that the pre-production process (as well as the delivery process) is analyzed in terms of the existence of hazards (risks) throughout the entire production cycle. The points of the production process, where these risks are the most real, are designated as critical points. These critical points are referred to as increased control points. For each of these points, approaches to the implementation of hazard control are formulated; control methods are determined; parameters by which the process will be controlled; normal (standard) process indicators and tolerances; actions of personnel and management in the presence of deviations; procedure for documenting the situation. At the same time, not only deviations, but also the entire current situation are subject to documentation, in order to demonstrate, if necessary, to consumers and/or external control bodies, including the state, the conditions in which one or another batch of food product was produced. ${ }^{\text {viii }}$

This standard combines the principles of HACCP and practical steps developed in the Code of the Commission on Food Products 28.10.1969 (Codex Alimentations Commission). ix By using verification requirements, he combines the prerequisite programs with the HACCP plan. Since the 1969 Code was proposed earlier, many countries and manufacturers developed and implemented their systems based on the requirements and recommendations of the 1969 Code. Meanwhile, the developers of the ISO 22000: 2005 standard believe that the principles of the Code and the standard are consistent, and a special table is given to confirm what in the appendix to the standard.

Let us compare the principles of HACCP in Ukraine (Order of the Ministry of Agrarian Policy and Food of Ukraine of 01.10.2012 No. 590) and in the Codex Alimentations Commission.
PRINCIPLE 1. In both documents, this principle implies the identification of hazards for the subsequent development of control methods. Hazard identification involves the identification of hazards; change of technological methods in production or (possible) replacement of raw materials and/or ingredients; the establishment of dangerous points (control points). As a result of such a study, points are established at which it is necessary to exercise control, and measures are developed for such control, and the significance of the risk of exceeding the permissible levels by hazardous factors is determined. The study of hazards should take into account factors that may be outside the direct control of the market operator. For example, food sales are outside the direct control of the market operator, but information about how products will be distributed (sold) can be affected, for example, by risk assessment. When conducting a hazard analysis, it is necessary to take into account issues related to food safety.

PRINCIPLE 2. In both documents, this principle implies the identification of critical points. These are the areas (components) of the production process that can generate real and obvious hazards to the quality of food products. At this stage, proper control methods should be developed. If there are no such control methods or it is assumed that they will be inefficient, the technological process should be restructured accordingly.

PRINCIPLE 3. In both documents, this principle assumes that critical limits will be set - these are extreme acceptable values (indicators) that separate the manufacture (release) of a safe product from a dangerous one. Critical limits should be measurable or, if it is not possible to establish measurable critical limits, visible to prove that CCP is under control. The value of the critical limits should be based on sufficient evidence that they will provide control over the process. Establishing a critical line, take into account the working error of the instrumentation used for monitoring. The value of critical limits is determined by the following criteria: requirements of the legislation; industry recommendations; Installations for production and hygiene practices are established by the HACCP team on the basis of its own research (in this case, confirmation (validation) is provided that these values are indeed critical limits). In some cases, in order to reduce the risk of exceeding critical limits due to deviations in the process, more stringent limits may be set operational limits to ensure that critical limits are not exceeded.

PRINCIPLE 4. In both documents, this principle assumes that monitoring procedures will be established at critical points. Monitoring should provide timely detection of loss of control for timely corrective actions. In case of inadequate control and deviations from critical limits occur, hazardous food can be produced. Given that the consequences of critical deviations at critical points lead to the release of hazardous food, monitoring procedures should be effective. If during monitoring, trends of loss of control at critical points are detected, preventive actions are taken (until actual

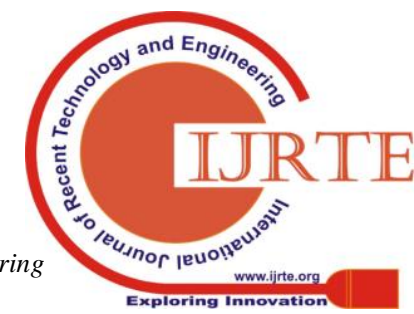


deviations are detected). Monitoring data should be checked by knowledgeable personnel and authorized, if necessary, to take corrective action. The market operator is obliged to implement effective monitoring procedures, which include monitoring parameters; monitoring frequency; responsibility for monitoring; registration of monitoring protocols.

PRINCIPLE 5. In both documents, this principle assumes that a system of corrective actions will be developed for each critical point. These actions can be applied immediately if monitoring shows a deviation from critical boundaries. The corrective action procedure should be documented in the appropriate procedures. Corrective actions should meet the following requirements: immediately regain control over the process; determine the causes of nonconformity; eliminate the causes of nonconformity; identify (identify) potentially hazardous products manufactured (released) at a time when the technological process was not under control (during periodic monitoring - since the last measurement with a positive result), and establish further processing with them. All steps to take corrective actions should be properly documented (for example, date, time, action, performer, next check). If corrective actions for a particular procedure are performed frequently (there are systemic deviations), then the effectiveness of corrective actions should be checked and procedures improved (for example, equipment calibration, validation of employee performance according to their responsibilities) or process adjustments, foodstuffs, or HACCP plan revisions.

PRINCIPLE 6. In both documents, this principle assumes that verification procedures (checks) will be established to determine if the HACCP system works correctly and efficiently. The purpose of the verification (s) is to obtain confidence that the HACCP plan is based on sound scientific evidence, provides control of the hazards associated with food and the process, and is carried out properly. The HACCP team uses the following information to conduct an inspection: handling complaints related to food safety; The results of laboratory monitoring of raw, partially processed or processed food; monitoring of CCT results; equipment calibration; results of checks, checks; checking records; variance analysis; checking the work of responsible personnel. The frequency of testing should be such as to confirm the effective operation of the HACCP system and depends on the characteristics of technological processes, type of food, productivity, staff qualifications, results of previous inspections, monitoring procedures, the number of discrepancies found, the nature of hazardous factors. Inspection is carried out at least once a year or is subject to changes in technological processes or food products that affect their safety. If the HACCP system has been implemented recently, it is recommended to check more often.

PRINCIPLE 7. In both documents, this principle assumes that procedures for maintaining records and documentation will be developed that will correspond to the production volume, features of technological processes and allow the market operator to verify the implementation and effectiveness of the control measures provided for by the HACCP system. HACCP system documentation is divided into basic - plan, HACCP procedures; operational protocols, records. Basic documentation includes: the composition of the HACCP team and its responsibilities; description of the food product and its intended consumption (use); proven production flow chart; hazard analysis; methodology for determining CCT; critical boundaries and their rationale; monitoring system, monitoring procedures for each CCP; the procedure for applying corrective measures; validation and verification procedure; HACCP document management procedures. Operational documentation includes minutes of meetings of the HACCP group; CCP monitoring protocols; protocols for the implementation of corrective measures; validation, verification protocols. All HACCP documents must be properly documented. The system must be efficient and understandable for staff. Documentation and record keeping can also be integrated into an existing Power documentation system using existing document forms (for example, technology journals). All protocols are stored in accordance with the requirements of the legislation. Protocols are important evidence of the effective functioning of the HACCP system when conducting an audit of the HACCP system by a government oversight body (oversight). Any changes to the entries are made only by authorized persons.

\section{Conclusion}

Thus, the principles of the Ukrainian HACCP system generally comply with international standards, in particular ISO 22000: 2005. This means that the legislation of Ukraine ensures that, in accordance with it, food products originating from Ukraine comply with the international requirements for controlling its manufacture. This is guaranteed by the control measures on the basis of the Law of Ukraine dated 05.18.2017 No. 2042-VIII regarding state control in the field of food safety. In accordance with Article 19 of this Law, state control measures are carried out in the form of an audit, inspection, pre-slaughter and post-mortem inspection, sampling, laboratory research (testing), documentary control, compliance testing, physical examination. As part of state control measures, state monitoring is carried out.

An audit of current procedures based on HACCP principles and current procedures developed by the market operator to comply with hygiene requirements should include checking the continuity and effectiveness of their application, including: 1) documentation; 2) record keeping; 3 ) processes affecting the safety of food and / or feed; 4) the system of internal control of the market operator; 5) corrective actions taken by the market operator as a result of analyzing the identified nonconformities; 6) staff qualifications.

The results of the audit should be taken into account when determining the degree of risk of the market operator (capacity) and the frequency of implementation of the planned measures of state control.

The same person does not

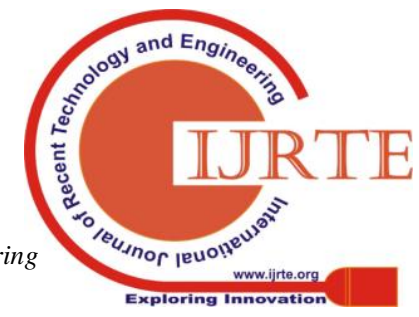


have the right to conduct an audit in the same capacity twice in a row.

Inspection includes verification of compliance with the requirements of 1 ) hygiene; 2) a corrective action plan developed and implemented by the market operator based on the results of preliminary checks; 3 ) incidents related to the safety of food and/or feed.

Inspections may include inspection of facilities, adjacent territories, premises, equipment and inventory, vehicles, as well as food and feed; raw materials, ingredients, auxiliary materials for processing, used for the preparation and production of food and feed, semi-finished products; items and materials in contact with food; cleaning and care products and processes, as well as pesticides; labeling, appearance and advertising.

The person conducting the inspection or audit has the right to conduct simple research (testing) if he has reasonable suspicions of non-compliance or if such studies are provided for by the annual state control plan.

\section{ACKNOWLEDGEMENTS:}

This article was supported in parts by Department of Constitutional and Administrative Law research work is state budget theme "Public-legal mechanism of guaranteeing Ukraine's national interests” (No. 55/13.01.02).

\section{REFERENCES}

[1] Odarchenko A. Improving the Competitiveness and Solvency of the Meat Industry Companies by Implementing the HACCP. Progressive technologies and technologies of food production of restaurant economy and trade. 2013; 1(17), part 2: 1054-109.

[2] Usenko A. Principles of Hazard Analysis and Critical Control Points (HACCP) in the international standard ISO 22000: 2005. Achievement of school. 2017; 15-22 November. Sofia: Byal GRAD-BG.

[3] Usenko A. Public administration in the field of implementation of Hazard Analysis and Critical Control Points (HACCP). Modern University Law Education and Science. 2018; 23 February, 1: 254-256.

[4] International Organization for Standardization. Food safety management systems - Requirements for any organization in the food chain (ISO 22000:2005). [Internet]. 2005 Sept 10 [cited 2018 Oct 28]. Available from: https://www.iso.org/standard/35466.html

[5] Galkina O. Administrative and legal principles of ensuring the safety and quality of food products in Ukraine: author's abstract. dis. Ph.D in Law. Kharkiv; 2017. 24 p.

[6] Pinyushko O. Food safety in a European way: scary, mandatory or just, European Truth. 2016; Jan 27. Available from: https://www.eurointegration.com.ua/rus/experts/2016/01/27/7043650/

[7] World Health Organization. Codex Alimentations. Food and Agricultural Organization of the United Nations, Rome. [Internet]. 1969 Oct 28 [cited 2018 Oct 28]. Available from: http://www.fao.org/docrep/005/y1579e/y1579e00.html.

i Odarchenko A. Improving the Competitiveness and Solvency of the Meat Industry Companies by Implementing the HACCP. Progressive technologies and technologies of food production of restaurant economy and trade. 2013; 1(17), part 2: 1054-109.

ii Galkina O. Administrative and legal principles of ensuring the safety and quality of food products in Ukraine: author's abstract. dis. Ph.D in Law. Kharkiv; 2017. 24 p.

iii Usenko A. Principles of Hazard Analysis and Critical Control Points (HACCP) in the international standard ISO 22000: 2005. Achievement of school. 2017; 15-22 November. Sofia: Byal GRAD-BG

iv Usenko A. Public administration in the field of implementation of Hazard Analysis and Critical Control Points (HACCP). Modern University Law Education and Science. 2018; 23 February, 1: 254-256.

v Pinyushko O. Food safety in a European way: scary, mandatory or just, European Truth. 2016; Jan 27. Available from: https://www.eurointegration.com.ua/rus/experts/2016/01/27/7043650/ vi Usenko A. Principles of Hazard Analysis and Critical Control Points (HACCP) in the international standard ISO 22000: 2005. Achievement of school. 2017; 15-22 November. Sofia: Byal GRAD-BG

vii Usenko A. Public administration in the field of implementation of Hazard Analysis and Critical Control Points (HACCP). Modern University Law Education and Science. 2018; 23 February, 1: 254-256.

viii International Organization for Standardization. Food safety management systems - Requirements for any organization in the food chain (ISO 22000:2005). [Internet]. 2005 Sept 10 [cited 2018 Oct 28]. Available from: https://www.iso.org/standard/35466.html

ix World Health Organization. Codex Alimentations. Food and Agricultural Organization of the United Nations, Rome. [Internet]. 1969 Oct 28 [cited 2018 Oct 28]. Available from: http://www.fao.org/docrep/005/y1579e/y1579e00.htm

\section{AUTHORS PROFILE}

My name is Usenko Anatoliy, I am Ph.D student, in National Aviation University, Kyiv, Ukraine my area of interest is management.

I am Julia Iurynets, Dsc., Assoc. Prof., National Aviation University, Kyiv, Ukraine

My name Yuriy Pyvovar, Ph.D., Prof., National Aviation University, Kosmonavta Komarova str. 1, 03058 Kyiv, Ukraine. My area of interest is management

My name is Leonid Belkin, I am Ph.D., Self-employed person, Kyiv, Ukraine. My are of interest is management. 